\title{
Grand Challenges in Microbiotechnology: Through the Prism of Microbiotechnology
}

\author{
Eric Altermann ${ }^{1,2}$ and William J. Hickey ${ }^{3 *}$ \\ ${ }^{1}$ AgResearch, Palmerston North, New Zealand, ${ }^{2}$ Riddet Institute, Massey University, Palmerston North, New Zealand, \\ ${ }^{3}$ Department of Soil Science, University of Wisconsin, Madison, WI, United States
}

Keywords: microbiotechnology, microbial community, bioremediation, microbial ecology, biodegradation, metabolic engineering, protein function, microbial consortia

\section{INTRODUCTION}

Microbes have conquered almost every conceivable space on earth-from high atmospheres to terrestrial and aquatic ecosystems to extreme places such as geothermal vents in the deep sea, oil reservoirs, or boiling hot springs. Survival in these varied environments necessitates a breathtaking span of genetic diversity, enabling the metabolism and synthesis of many different substrates for both energy creation and biomass buildup and to gain an evolutionary advantage over other life forms sharing the same ecosystem. Of particular biotechnological interest are molecules referred to as secondary metabolites that often feature a unique chemical makeup and can encompass functions such as ion scavenging, quorum sensing, or act as antimicrobials.

With the advent of anthropogenic impacts on our planet, such as the change or creation of new ecosystems (e.g., waste water treatment plants, large scale commercial fermentation processes) or the deposition of novel compounds and toxic pollutants into the environment, microbes have shown remarkable adaptability to utilize these newly introduced materials as novel sources of energy.

It is this surprisingly vast and adaptable biochemical potential of microbes that we have come to realize and exploit for specific tasks ranging from fermentation processes modifying material properties, to the manufacture of high-value stereospecific chemicals and polymers, to the breakdown of hazardous substances.

The application of microbes to industrial processes is commonly known as Microbiotechology. Under this umbrella, many different subareas are combined and have been explored over the last decade in Frontiers in Microbiology specialty section on "Microbiotechnology" (previously "Microbiotechnology, Ecotoxicology and Bioremediation").

\section{MOVING RESEARCH OVER A DECADE}

Since 2011, Micro Bio Technology (MBT) has been dedicated to offer a platform for high quality research, investigating the exploitation of microbial genetic diversity toward environmental and industrial applications. How did research push the boundaries of our knowledge and understanding of microbial processes in nature and their biotechnological application?

Bioremediation via methanotrophs to effect aerobic degradation of chlorinated hydrocarbons, was one of the most cited publications in the first year of this specialty (Semrau, 2011). Chlorinated hydrocarbons are widely used as plastics, solvents, insulators, or pesticides, they are now ubiquitous in the environment and the ecotoxicity of some of these (e.g., dioxins, DDT) have particular concerns in environmental health and toxicology. The focus on biodegradation and bioremediation was further elaborated by a perspective on how to quantify biodegradation of substances from 
a regulatory perspective (Thouand et al., 2011)and the development of genetic tools to improve biodegradation by specific microbes (Hickey, 2011). Following this line of research, publications emerged targeting the biodegradation of many different chemical classes through classical genomics approaches and the characterization of microbial communities (Figure 1, 2011-2012). In the following 2 years, a notable shift was observed toward synthetic biology, microbiotechnology, and metabolic engineering driven by an increasing genome space (Figure 1, 2013-2014) (De Gannes et al., 2013; Moe-Behrens et al., 2013; Elena et al., 2014; Rosano and Ceccarelli, 2014).

From 2015 onwards, the progressive drop in DNA sequencing cost enabled the investigation of microbial communities in much greater detail and a prominent research area on microbial communities was established and more recently consolidated under "metagenomic" research. But not only the community structure saw a much more in-depth exploration, the ready availability of draft genome sequences of individual microbes and new gene and genome editing tools enabled substantial advances in metabolic engineering. In particular the exploitation of microbial molecule and polymer synthesis such as exopolysaccharides, pigments, lipids, or biosurfactants has received much attention (Figure 1, 2015-2018) (Rosano and Ceccarelli, 2014; Antoniou et al., 2015; Bonugli-Santos et al., 2015; Giddings et al., 2015; Ishii et al., 2015; Kracke et al., 2015; Moscovici, 2015; Schmid et al., 2015; Torino et al., 2015; Uzoigwe et al., 2015; Whitfield et al., 2015; Zeldes et al., 2015; De Almeida et al., 2016; Ghosal et al., 2016; Gill et al., 2016; Gouda et al., 2016; Jugder et al., 2016; Liew et al., 2016; Minhas et al., 2016; Santiago et al., 2016; Shchegolkova et al., 2016; Singh et al., 2016; Thijs et al., 2016).

Most recently, the realization that a comprehensive understanding of biological ecosystems as a whole is key to more advanced biotechnological approaches has led to an even stronger integration of 'omics technologies into microbial ecology, interrogating bacterial communities for their

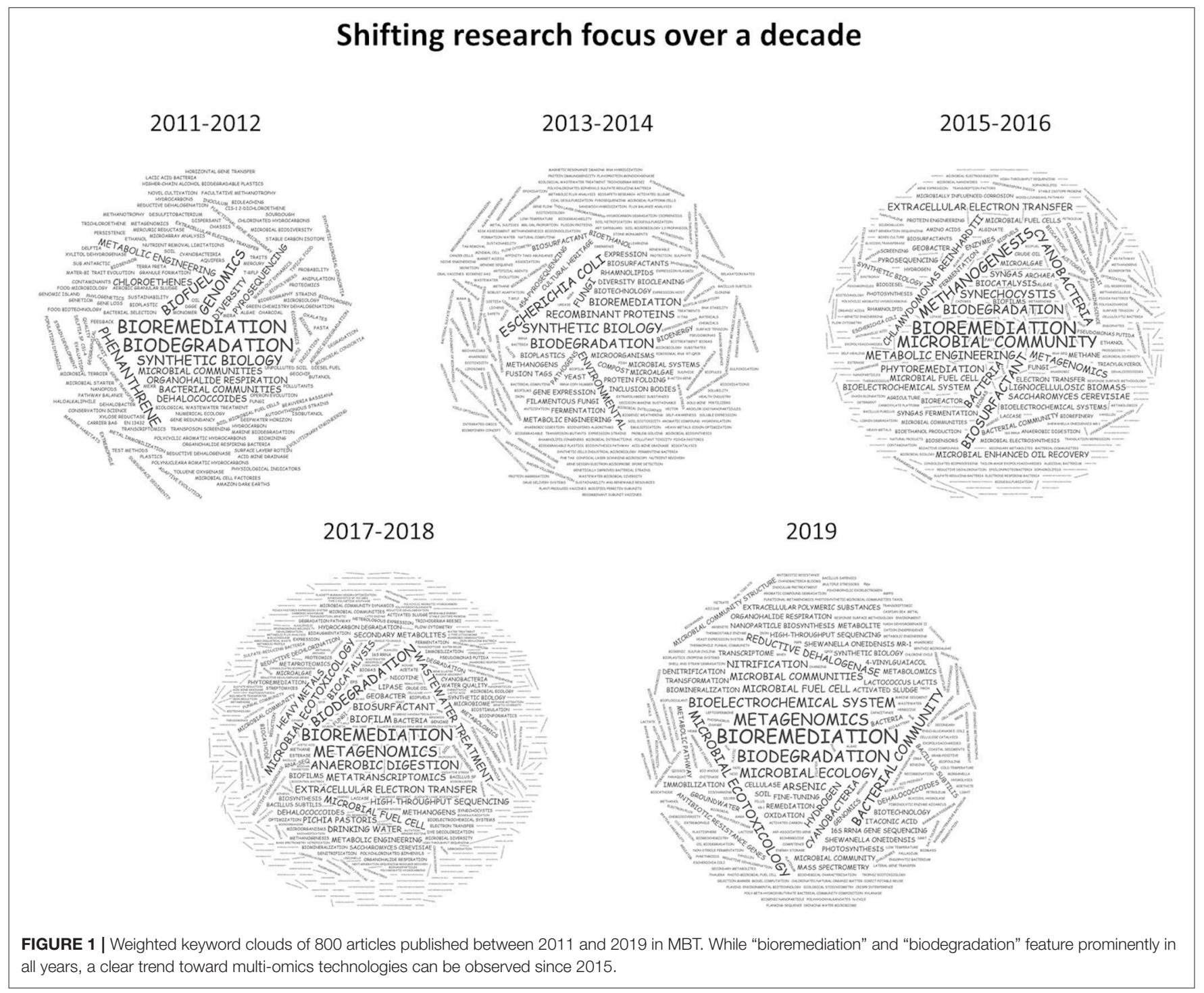


mechanistic function toward bioremediation and biodegradation (Figure 1, 2019) (Abbas et al., 2019; Carrillo-Barragan et al., 2019; Chonova et al., 2019; Crouzet et al., 2019; Cycon et al., 2019; Jacquin et al., 2019; Jaiswal et al., 2019; Kantor et al., 2019; Li F. et al., 2019; Li J. et al., 2019; Marco and Abram, 2019; Meng et al., 2019; Miller et al., 2019; Pinnell and Turner, 2019; Ragab et al., 2019; Rocca et al., 2019; Sengupta et al., 2019; Suri et al., 2019; Xiao et al., 2019; Xu et al., 2019).

A developing area of microbiotechnology "phytoremediation" was defined as "the synergistic actions of plants and microorganisms [...] to clean up soils [and other ecosystems]" (Thijs et al., 2016). While the independent investigation of different microbes or plants has been investigated for bioremediation or the production of compounds, the synergistic interactions between both agents is key to understand and fully exploit their potential for both biotechnical applications and persistence. Therefore, more research into holistic, mechanistic examinations of entire ecosystems will be required moving into the future.

\section{MOVING INTO THE FUTURE OF MICROBIOTECHNOLOGY: GRAND CHALLENGES}

'OMICs technologies have an ever more prominent presence in publications in all areas of microbiotechnology and their impact on accelerating our knowledge framework can hardly be overstated. 'OMICS technologies were initially often thought of as only DNA-based technologies, such as high-throughput genome sequencing, metagenomics and to a smaller degree, metatranscriptomics. With the advent of high-throughput approaches in other disciplines, 'omics technologies now also include metaproteomics, metabolomics, epigenetics, and phenomics, alongside other emerging 'omics studies. However, the common pitfall of using these high-throughput technologies is to utilize them as a mere looking glass. This one-dimensional approach has led to a large number of descriptive science publications that, while delivering new insights into microbial community composition and their changes in response to time or stressors, lack true mechanistic insights on community and designed consortia levels.

The functional link between in silico 'OMICS technologies and in vitro/in vivo engineering, experiments, validation, and applications of individual microorganisms and strategically designed consortia holds many grand challenges, two of which we envision are a Grand Challenge in (1) Integrative Molecular Analysis (IMA) and (2) Microbial Community Mechanisms (MCM).

A first dimension of the IMA Grand Challenge will be to gain an understanding of how changes in the amounts and types of cellular molecules (e.g., mRNA, proteins) are inter-related and how the collective dynamics of these molecules is ultimately manifested in cellular activities. Achieving this goal would be a quantum leap in fundamental microbiology and, consequently, enable attendant advances in applied microbiological fields ranging from design of biosynthetic pathways to managing microbes in the environment.

A key hurdle in attaining this goal is the mismatch between the linear approaches used to study the molecules that mediate microbial processes and the non-linear mechanisms through which these molecules mediate cellular behaviors. Currently, classes of key molecules are studied individually, removed from the cells and all other molecules with which they would natively interact to create dynamic systems. For example, detection and quantification of mRNA (via hybridization array, RNAseq, or qPCR) is widely used as a proxy for cognate protein levels (and by extension, an activity/phenotype of interest), yet there is ample evidence that no such strict correspondence exists between these molecules. Instead, types and levels of cellular proteins and metabolites (and hence phenotypes) are the result of numerous types and levels of control. Furthermore, the importance of any one of these regulatory controls may vary between organisms or within an organism depending on the particular protein or condition of the cell.

Obtaining a more rigorous understanding of the cellular processes that control microbial life will require a dramatic revolution in the technologies and approaches applied in molecular studies. Advanced technologies are needed that enable multiple molecule types to be queried simultaneously, ideally within cells. This grand challenge in technological development lies at the nexus of microbiology with many other fields including chemistry, biochemistry and biophysics, and will be a truly interdisciplinary effort.

Meeting the IMA Grand Challenge will require a second dimension by advancing technologies and methodologies for deciphering gene function. This is a multifaceted issue and encompasses investigation of gene function in cultured organisms as well as functions for those that exist only in silico and originate in genome sequence derived from environmental DNA extracts. For cultured organisms, genetic manipulations that are essential to decipher, or alter, functions of gene products have not advanced at the same rapid pace as other nucleic acid technologies and represent a key bottleneck in efforts to deepen insights into microbial biology.

Some relatively recent developments in genetic engineering, such as recombineering and CRISPR-based approaches, circumvent some of the limitations of conventional methods. But, as with the conventional approaches, their application to any given organism typically requires resolution of many issues through empirical testing, which effectively restricts the development and application to a relatively small number of laboratories. Thus, achievement of this Grand Challenge would be facilitated by the development of centralized efforts within government institutions that focus on the development and dissemination of technologies in partnerships with academia.

A third dimension to the IMA Grand Challenge is deciphering biological roles for the large and ever-expanding database of genes with unknown function. These efforts rely heavily on computational approaches for function prediction, and improvements in computation will be essential to advance this field. Specifically, to discover truly novel functions, a revolution in computational methods is needed that would allow de novo 
assignment of function with little, or no, reference to information in existing databases. Computational methods are also needed that include molecular interactions in function prediction, since the activities of the majority of proteins likely arise from such processes. Advancements have already been made in predicting protein-protein interactions, and these need to be improved and expanded to include the diversity of molecules that exist within the cell. Beyond the computational challenges in identifying putatively novel functions, there are also advancements needed in genetic systems (see above) that would be needed to prove function and provide a means for translating the potential of novel genes into products or functions.

The MCM Grand Challenge centers on obtaining comprehensive mechanistic understanding on how microbial communities interact with each other, with potential hosts and with the environment. It is clear that microbes in isolation only display a fraction of their genetic potential and gains achieved by understanding and exploiting synergistic interactions could revolutionize microbiotechnolgy in all its aspects. Such understanding can only be achieved by utilizing and further developing gene and genome engineering tools alongside the plethora of 'omics technologies. Similar to the synergistic play of multiple microbes together, we must develop new systems and technological infrastructure to successfully mature, combine, interrogate and visualize the high-dimensional 'OMICS data so that they can inform mathematical models and aid in strategically select gene candidates for functional investigation and the deliberate assembly of microbial consortia to achieve a

\section{REFERENCES}

Abbas, S. Z., Rafatullah, M., Khan, M. A., and Siddiqui, M. R. (2019). Bioremediation and electricity generation by using open and closed sediment microbial fuel cells. Front. Microbiol. 9:3348. doi: 10.3389/fmicb.2018.03348

Antoniou, E., Fodelianakis, S., Korkakaki, E., and Kalogerakis, N. (2015). Biosurfactant production from marine hydrocarbon-degrading consortia and pure bacterial strains using crude oil as carbon source. Front. Microbiol. 6:274. doi: $10.3389 /$ fmicb. 2015.00274

Bonugli-Santos, R. C., Dos Santos Vasconcelos, M. R., Passarini, M. R. Z., Vieira, G. a. L., Lopes, V. C. P., Mainardi, P. H., et al. (2015). Marine-derived fungi: diversity of enzymes and biotechnological applications. Front. Microbiol. 6:269. doi: $10.3389 /$ fmicb.2015.00269

Carrillo-Barragan, P., Bowler, B., Dolfing, J., Sallis, P., and Gray, N. D. (2019). Enrichment and characterisation of a mixed-source ethanologenic community degrading the organic fraction of municipal solid waste under minimal environmental control. Front. Microbiol. 10:722. doi: $10.3389 /$ fmicb. 2019.00722

Chonova, T., Kurmayer, R., Rimet, F., Labanowski, J., Vasselon, V., Keck, F., et al. (2019). Benthic diatom communities in an alpine river impacted by waste water treatment effluents as revealed using DNA metabarcoding. Front. Microbiol. 10:653. doi: 10.3389/fmicb.2019.00653

Crouzet, O., Consentino, L., Pétraud, J.-P., Marrauld, C., Aguer, J.-P., Bureau, S., et al. (2019). Soil photosynthetic microbial communities mediate aggregate stability: influence of cropping systems and herbicide use in an agricultural soil. Front. Microbiol. 10:1319. doi: 10.3389/fmicb.2019.01319

Cycon, M., Mrozik, A., and Piotrowska-Seget, Z. (2019). Antibiotics in the soil environment-Degradation and their impact on microbial activity and diversity. Front. Microbiol. 10:338. doi: 10.3389/fmicb.2019.00338

De Almeida, D. G., Soares Da Silva, R. D. C. F., Luna, J. M., Rufino, R. D., Santos, V. A., Banat, I. M., et al. (2016). Biosurfactants: promising biotechnological goal. The MCM Grand Challenge will not be able to be achieved through the scope of Microbiotechnology alone-it will require a truly inter-disciplinary collaboration across many science disciplines.

The extent to which research in microbiotechnology can be translated into novel societal uses will be dependent upon the depth to which these microbial systems are understood. Thus, revolutionary advancements in how, or what, microbial processes are employed to achieve some goal must be preceded by advancements in fundamental science such as those presented above. These advancements would move biosciences well beyond the current age of 'OMICs, technologies, which have been essential in the evolution of biosciences, but which lack the multidimensionality that will be needed in the next generation of analytical tools to gain deeper insights into cellular functions and, consequently, develop new ways in which the potential of microbial systems is captured.

\section{AUTHOR CONTRIBUTIONS}

EA and WH have devised and written the Grand Microbiotechnology Challenge.

\section{ACKNOWLEDGMENTS}

We are grateful to Helene Jensen for providing the comprehensive keyword datasets on all the manuscripts published in MBT. molecules for petroleum biotechnology advances. Front. Microbiol. 7:1718. doi: $10.3389 /$ fmicb. 2016.01718

De Gannes, V., Eudoxie, G., and Hickey, W. (2013). Insights into fungal communities in composts revealed by 454-pyrosequencing: implications for human health and safety. Front. Microbiol. 4:164. doi: 10.3389/fmicb.2013.00164

Elena, C., Ravasi, P., Castelli, M., Peiru, S., and Menzella, H. (2014). Expression of codon optimized genes in microbial systems: current industrial applications and perspectives. Front. Microbiol. 5:21. doi: 10.3389/fmicb.2014. 00021

Ghosal, D., Ghosh, S., Dutta, T. K., and Ahn, Y. (2016). Current state of knowledge in microbial degradation of polycyclic aromatic hydrocarbons (PAHs): a review. Front. Microbiol. 7:1369. doi: 10.3389/fmicb.2016.01369

Giddings, C. G. S., Nevin, K. P., Woodward, T., Lovley, D. R., and Butler, C. S. (2015). Simplifying microbial electrosynthesis reactor design. Front. Microbiol. 6:468. doi: 10.3389/fmicb.2015.00468

Gill, S. S., Gill, R., Trivedi, D. K., Anjum, N. A., Sharma, K. K., Ansari, M. W., et al. (2016). Piriformospora indica: potential and significance in plant stress tolerance. Front. Microbiol. 7:332. doi: 10.3389/fmicb.2016.00332

Gouda, S., Das, G., Sen, S. K., Shin, H.-S., and Patra, J. K. (2016). Endophytes: a treasure house of bioactive compounds of medicinal importance. Front. Microbiol. 7:1538. doi: 10.3389/fmicb.2016.01538

Hickey, W. (2011). Development of Tools for genetic analysis of phenanthrene degradation and nanopod production by Delftia sp. Cs1-4. Front. Microbiol. 2:187. doi: 10.3389/fmicb.2011.00187

Ishii, T., Kawaichi, S., Nakagawa, H., Hashimoto, K., and Nakamura, R. (2015). From chemolithoautotrophs to electrolithoautotrophs: $\mathrm{CO}_{2}$ fixation by $\mathrm{Fe}(\mathrm{II})$ oxidizing bacteria coupled with direct uptake of electrons from solid electron sources. Front. Microbiol. 6:994. doi: 10.3389/fmicb.2015.00994

Jacquin, J., Cheng, J., Odobel, C., Pandin, C., Conan, P., Pujo-Pay, M., et al. (2019). Microbial ecotoxicology of marine plastic debris: a review on 
colonization and biodegradation by the "plastisphere". Front. Microbiol. 10:865. doi: $10.3389 /$ fmicb.2019.00865

Jaiswal, S., Singh, D. K., and Shukla, P. (2019). Gene editing and systems biology tools for pesticide bioremediation: a review. Front. Microbiol. 10:87. doi: $10.3389 /$ fmicb.2019.00087

Jugder, B.-E., Ertan, H., Bohl, S., Lee, M., Marquis, C. P., and Manefield, M. (2016). Organohalide respiring bacteria and reductive dehalogenases: key tools in organohalide bioremediation. Front. Microbiol. 7:249. doi: 10.3389/fmicb.2016.00249

Kantor, R. S., Miller, S. E., and Nelson, K. L. (2019). The Water microbiome through a pilot scale advanced treatment facility for direct potable reuse. Front. Microbiol. 10:993. doi: 10.3389/fmicb.2019.00993

Kracke, F., Vassilev, I., and Krömer, J. O. (2015). Microbial electron transport and energy conservation - the foundation for optimizing bioelectrochemical systems. Front. Microbiol. 6:575. doi: 10.3389/fmicb.2015.00575

Li, F., An, X., Wu, D., Xu, J., Chen, Y., Li, W., et al. (2019). Engineering microbial consortia for high-performance cellulosic hydrolyzates-fed microbial fuel cells. Front. Microbiol. 10:409. doi: 10.3389/fmicb.2019. 00409

Li, J., Zhang, Y., Zheng, S., Liu, F., and Wang, G. (2019). Anaerobic bacterial immobilization and removal of toxic $\mathrm{Sb}(\mathrm{III})$ coupled with $\mathrm{Fe}(\mathrm{II}) / \mathrm{Sb}(\mathrm{III})$ oxidation and denitrification. Front. Microbiol. 10:360. doi: $10.3389 /$ fmicb. 2019.00360

Liew, F., Martin, M. E., Tappel, R. C., Heijstra, B. D., Mihalcea, C., and Köpke, M. (2016). Gas Fermentation-A Flexible Platform for Commercial Scale Production of Low-Carbon-Fuels and Chemicals from Waste and Renewable Feedstocks. Front. Microbiol. 7:694. doi: 10.3389/fmicb.2016. 00694

Marco, D. E., and Abram, F. (2019). Editorial: using genomics, metagenomics and other "omics" to assess valuable microbial ecosystem services and novel biotechnological applications. Front. Microbiol. 10:151. doi: $10.3389 /$ fmicb.2019.00151

Meng, Q., Yang, W., Men, M., Bello, A., Xu, X., Xu, B., et al. (2019). Microbial community succession and response to environmental variables during cow manure and corn straw composting. Front. Microbiol. 10:529. doi: $10.3389 /$ fmicb.2019.00529

Miller, J. I., Techtmann, S., Fortney, J., Mahmoudi, N., Joyner, D., Liu, J., et al. (2019). Oil hydrocarbon degradation by Caspian sea microbial communities. Front. Microbiol. 10:995. doi: 10.3389/fmicb.2019.00995

Minhas, A. K., Hodgson, P., Barrow, C. J., and Adholeya, A. (2016). A Review on the assessment of stress conditions for simultaneous production of microalgal lipids and carotenoids. Front. Microbiol. 7:546. doi: 10.3389/fmicb.2016.00546

Moe-Behrens, G., Davis, R., and Haynes, K. (2013). Preparing synthetic biology for the world. Front. Microbiol. 4:5. doi: 10.3389/fmicb.2013.00005

Moscovici, M. (2015). Present and future medical applications of microbial exopolysaccharides. Front. Microbiol. 6:1012. doi: 10.3389/fmicb.2015.01012

Pinnell, L. J., and Turner, J. W. (2019). Shotgun metagenomics reveals the benthic microbial community response to plastic and bioplastic in a coastal marine environment. Front. Microbiol. 10:1252. doi: 10.3389/fmicb.2019.01252

Ragab, A. A., Katuri, K. P., Ali, M., and Saikaly, P. E. (2019). Evidence of spatial homogeneity in an electromethanogenic cathodic microbial community. Front. Microbiol. 10:1747. doi: 10.3389/fmicb.2019.01747

Rocca, J. D., Simonin, M., Blaszczak, J. R., Ernakovich, J. G., Gibbons, S. M., Midani, F. S., et al. (2019). The microbiome stress project: toward a global metaanalysis of environmental stressors and their effects on microbial communities. Front. Microbiol. 9:3272. doi: 10.3389/fmicb.2018.03272

Rosano, G. L., and Ceccarelli, E. A. (2014). Recombinant protein expression in Escherichia coli: advances and challenges. Front. Microbiol. 5:172. doi: $10.3389 /$ fmicb.2014.00172

Santiago, M., Ramírez-Sarmiento, C. A., Zamora, R. A., and Parra, L. P. (2016). Discovery, molecular mechanisms, and industrial applications of cold-active enzymes. Front. Microbiol. 7:1408.
Schmid, J., Sieber, V., and Rehm, B. (2015). Bacterial exopolysaccharides: biosynthesis pathways and engineering strategies. Front. Microbiol. 6:496. doi: $10.3389 /$ fmicb. 2015.00496

Semrau, J. (2011). Bioremediation via methanotrophy: overview of recent findings and suggestions for future research. Front. Microbiol. 2:209. doi: 10.3389/fmicb.2011.00209

Sengupta, K., Swain, M. T., Livingstone, P. G., Whitworth, D. E., and Saha, P. (2019). Genome sequencing and comparative transcriptomics provide a holistic view of 4-nitrophenol degradation and concurrent fatty acid catabolism by Rhodococcus sp. Strain BUPNP1. Front. Microbiol. 9:3209. doi: 10.3389/fmicb.2018.03209

Shchegolkova, N. M., Krasnov, G. S., Belova, A. A., Dmitriev, A. A., Kharitonov, S. L., Klimina, K. M., et al. (2016). Microbial community structure of activated sludge in treatment plants with different wastewater compositions. Front. Microbiol. 7:90. doi: 10.3389/fmicb.2016.00090

Singh, G., Jawed, A., Paul, D., Bandyopadhyay, K. K., Kumari, A., and Haque, S. (2016). Concomitant production of lipids and carotenoids in rhodosporidium toruloides under osmotic stress using response surface methodology. Front. Microbiol. 7:1686. doi: 10.3389/fmicb.2016.01686

Suri, N., Gassara, F., Stanislav, P., and Voordouw, G. (2019). Microbially enhanced oil recovery by alkylbenzene-oxidizing nitrate-reducing bacteria. Front. Microbiol. 10:1243. doi: 10.3389/fmicb.2019.01243

Thijs, S., Sillen, W., Rineau, F., Weyens, N., and Vangronsveld, J. (2016). Towards an enhanced understanding of plant-microbiome interactions to improve phytoremediation: engineering the metaorganism. Front. Microbiol. 7:341. doi: $10.3389 /$ fmicb.2016.00341

Thouand, G., Durand, M., Maul, A., Gancet, C., and Blok, H. (2011). New concepts in the evaluation of biodegradation/persistence of chemical substances using a microbial inoculum. Front. Microbiol. 2:164. doi: 10.3389/fmicb.2011.00164

Torino, M., Font De Valdez, G., and Mozzi, F. (2015). Biopolymers from lactic acid bacteria. Novel applications in foods and beverages. Front. Microbiol. 6:834. doi: $10.3389 /$ fmicb.2015.00834

Uzoigwe, C., Burgess, J. G., Ennis, C. J., and Rahman, P. K. S. M. (2015). Bioemulsifiers are not biosurfactants and require different screening approaches. Front. Microbiol. 6:245. doi: 10.3389/fmicb.2015.00245

Whitfield, G. B., Marmont, L. S., and Howell, P. L. (2015). Enzymatic modifications of exopolysaccharides enhance bacterial persistence. Front. Microbiol. 6:471. doi: 10.3389/fmicb.2015.00471

Xiao, S., Zhang, Q., Chen, X., Dong, F., Chen, H., Liu, M., et al. (2019). Speciation distribution of heavy metals in uranium mining impacted soils and impact on bacterial community revealed by high-throughput sequencing. Front. Microbiol. 10:1867. doi: 10.3389/fmicb.2019.01867

Xu, D., Ding, W., Ke, W., Li, F., Zhang, P., and Guo, X. (2019). Modulation of metabolome and bacterial community in whole crop corn silage by inoculating homofermentative Lactobacillus plantarum and heterofermentative Lactobacillus buchneri. Front. Microbiol. 9:3299. doi: 10.3389/fmicb.2018.03299

Zeldes, B. M., Keller, M. W., Loder, A. J., Straub, C. T., Adams, M. W. W. and Kelly, R. M. (2015). Extremely thermophilic microorganisms as metabolic engineering platforms for production of fuels and industrial chemicals. Front. Microbiol. 6:1209. doi: 10.3389/fmicb.2015.01209

Conflict of Interest: The authors declare that the research was conducted in the absence of any commercial or financial relationships that could be construed as a potential conflict of interest.

Copyright $\odot 2020$ Altermann and Hickey. This is an open-access article distributed under the terms of the Creative Commons Attribution License (CC BY). The use, distribution or reproduction in other forums is permitted, provided the original author(s) and the copyright owner(s) are credited and that the original publication in this journal is cited, in accordance with accepted academic practice. No use, distribution or reproduction is permitted which does not comply with these terms. 